\title{
Management of Occlusion by Global Prosthetic Rehabilitation: a Clinical Case
}

\author{
Zenati $\mathrm{L}^{1 *}$, Boukemouche $\mathrm{A}^{2}$ and Boukais $\mathbf{H}^{3}$ \\ ${ }^{1}$ Prosthodontics, Saad Dahlab University, Algeria \\ ${ }^{2}$ Prosthodontics and Implantology, Ain Naadja Military Hospital, Algeria \\ ${ }^{3}$ Pathology and Oral Surgery, University of Blida, Algeria
}

*Corresponding author: Smriti Jagdhari Golhar, Assistant Professor, Department of Oral Medicine \& Radiology, VSPM'S Dental College \& Research Center, C/O Dr. Anil Golhar, 256 Ramdaspeth, Nagpur, Maharashtra, India

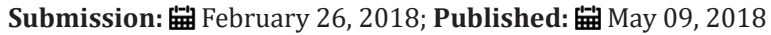

\begin{abstract}
Edentulism is accompanied by musculo-articular disorders that must be diagnosed and treated in the pre-prosthetic phase necessary to ensure the success and durability of the prosthetic restoration.

Clinical observation: This is a clinical study realized at the dental clinic Zabana of Blida, the patient consulted for a functional and aesthetic purpose (presence of anterior and posterior inverted occlusion) associated with a TDM (dysfunction of the manducatory system). The treatment was instituted following the clinical examination and secondary examinations as: axiographic recording and occlusal analysis on semi-adaptable articulator

Result and discussion: The port of occlusal gutter performed in centric relation position was 3 months and weaning was among a decrease in joint pain, Occlusal dysfunction was restored through fixed and removable prosthetic restorations the axiographic record before and after treatment shows the change of the condylar position following the change of the occlusion of our patient with an increase of the condylar slope of $3^{\circ}$.

Conclusion: The global restoration of the occlusion allowed to harmonize the mandibular movements and to guarantee a perennial occlusion and thus the condylar position thus limiting the TDM problems.
\end{abstract}

Keywords: Occlusal therapeutic; Occlusal splint; TMJ; Axiographic tracing; Global prosthetic rehabilitation

\section{Introduction}

Occluso-prosthetic rehabilitation aims is to restore in a sustainable way all the functions disturbed by edentation whether partial or total.

In the presence of the occluso-temporo- mandibular disc problems, the task of the dentist becomes more complicated because edentulism is accompanied by a muscular articular disorder that must be diagnosed and treated pre-prosthetic phase necessary to ensure the success and sustainability of prosthetic restoration.

As we all know the disruption of occlusal functions (centering, wedging, guiding) will result in occlusal muscular articular disorders, among the evocative signs: cracking; snap; mandibular deviation; prematurity and occlusal interference, as well as a decrease in the vertical dimension [1-3].

\section{Approach and Diagnostic Criteria}

This is a clinical study carried out at the Zabana clinical dental Blida, the patient consulted for a functional and aesthetic purpose (presence of anterior and posterior inverted occlusion) associated with a DAM (dysfunction of the manducatory system).

Clinical examination revealed a concave facial profile with prominence of the lower lip that the patient aesthetically refused; audible creaks in the temporomandibular joints in the end of opening movements. The mouth opening was three fingers with non-coincidence of the upper and lower incisor line. The examination of the temporomandibular joints resulted in a cracked articular sound at the end of the mouth opening movement [4-8].

Occlusal examination revealed an inverted occlusion with no wedging, guiding and centering mandibular predisposing to joint overload, upper arch restoration by a 15-16-17 metal-resin bridge; metal-resin crown on the 23 and a flexible partial replacing the 1415-16-17 (Figure 1). At the lower arch are two metal-resin bridges ranging from 34 to 37 and from 45 to 47 .

This relevant clinical examination is completed by an axiographic examination (Quick axis of the firm Fag) followed by an occlusal analysis and which will be thoroughly analyzed. The 
axiograph is an apparatus composed by a kinematic facial bow, an occlusal fork, a recording stylus placed on point 0 "equivalent of the arbitrary hinge axis" and which draws the condylar path on the para-condylar flag during movement, mandibular propulsion or mouth opening.

The axiography registration recorded during joint displacement confirms the positive diagnosis of a disc displacement with reduction at the end of the mouth opening movement as well as the actual value of the condylar slope estimated at $50^{\circ}$ which will be used in future programming the condylar slope of the semi-adaptable articulator Sam II, the angle of Bennett will be set according to the formula of Hanau and have the value of $18,25^{\circ}$ (Figure 2-5).

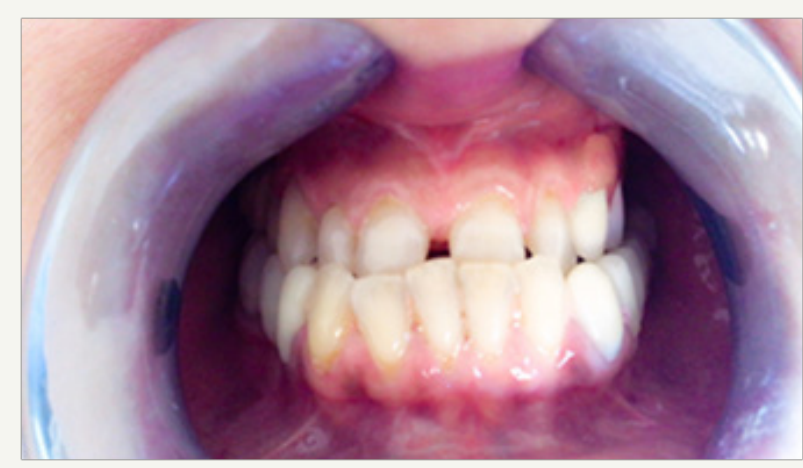

Figure 1: Initial occlusion.

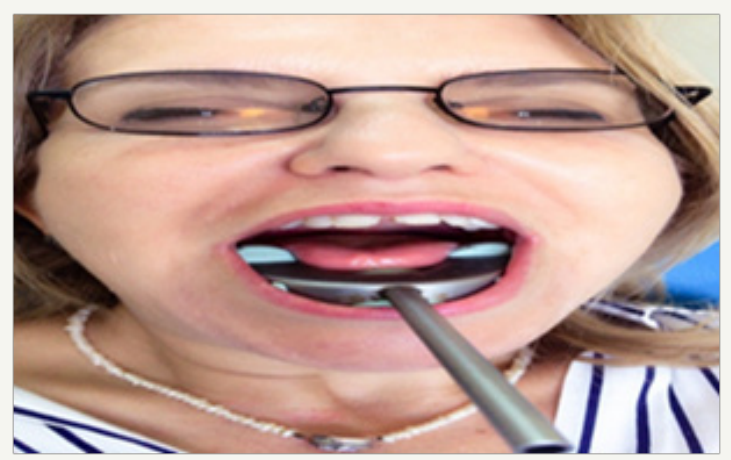

Figure 2: An occlusal fork charged with heavy PVS.

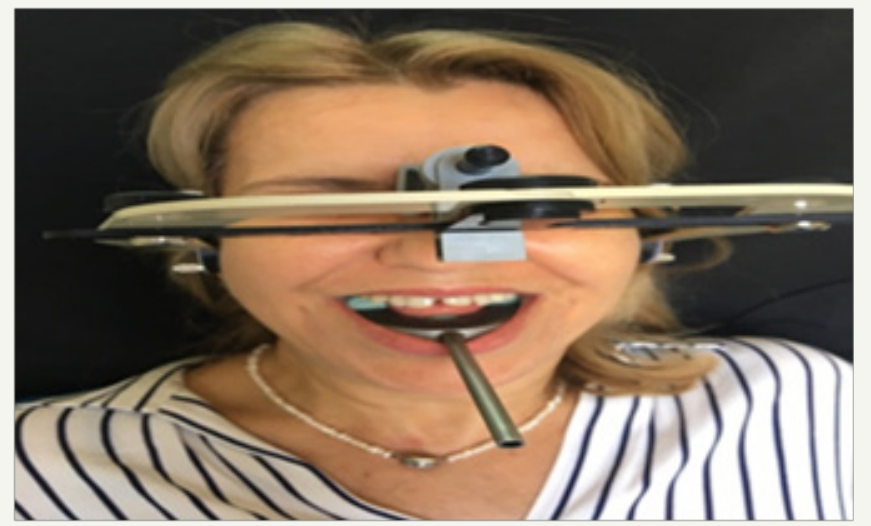

Figure 3: Kinematic facial bow on place.

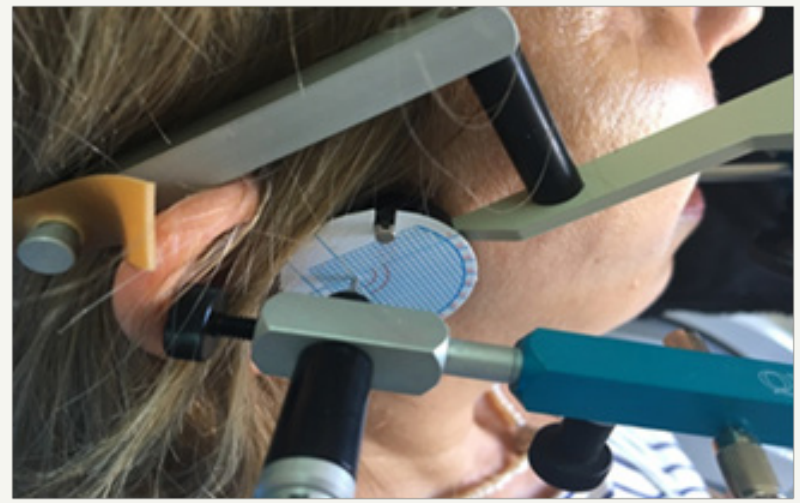

Figure 4: Stylus behind the point 0 equivalent the hinge axis.

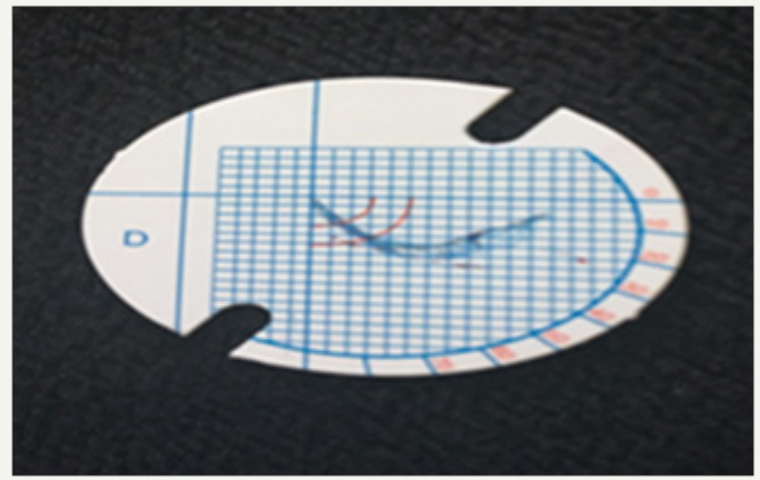

Figure 5: Axiography registration before treatment showing the diagnosis of disc displacement with reduction.

\section{Therapeutic Attitude}

The therapeutic approach was aimed at the three etiological axes probably responsible for TMD; as a reminder:

a) Axis I: The structural dimension: local somatic aspect including musculoskeletal organization, TMJ, and occlusion.

b) Axis II: The psychosocial dimension: psychic aspect of the individual in his environmental and cultural context influencing his interpretation of psycho-emotional factors and his manducatory behavior.

c) Axis III: The biological dimension: general somatic (systemic) aspect and genetic substratum influencing the muscular articular field.

We advocate a pragmatic approach to DTM, based on logic of simplicity, confronting clear diagnostic data and favoring simple, non-invasive, reversible and effective therapies.

Current international recommendations propose first-line use of reversible and non-invasive procedures:

A. Information and patient education to better understand his state of health

B. Cognitive behavioral therapy

C. Occlusal splint 
D. Prosthetic restorations with the right vertical dimension and centric relation

The initial treatment begins with preliminary upper and lower imprints of irreversible hydro colloid (Figure 6 \& 7).

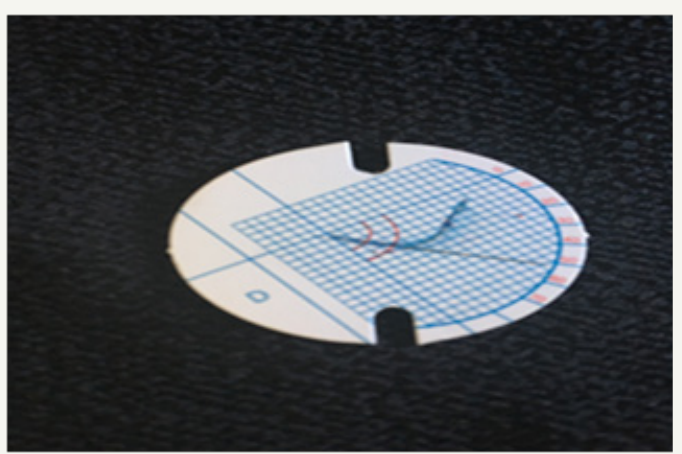

Figure 6: Condylar slope evaluated to $50^{\circ}$.

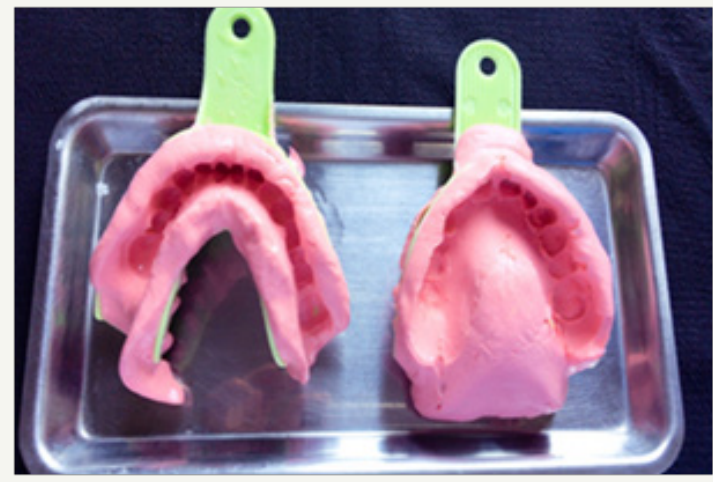

Figure 7: Preliminary impression with alginate.

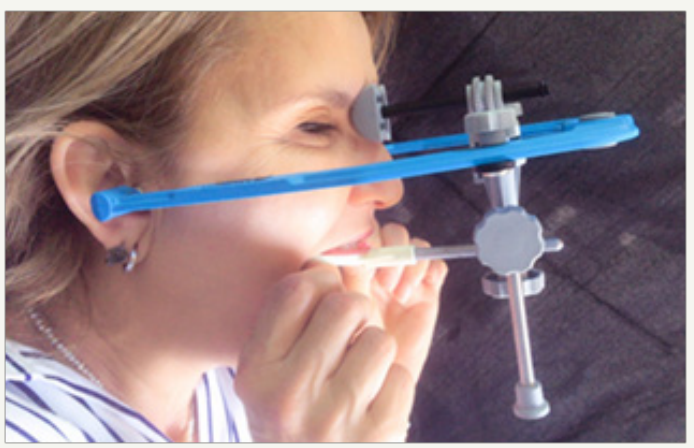

Figure 8: Facial arc on place, profile view.
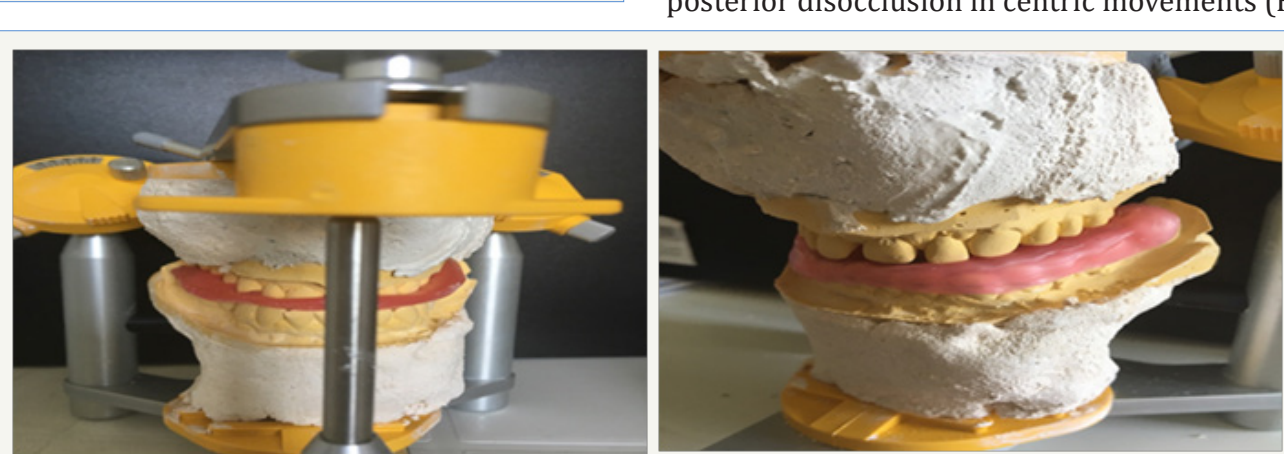

We proceeded to the transfer of the upper model to the upper branch of the Arcon-type semi-adaptable SAM II articulator, thus materializing the franking plane thanks to an arbitrary facial bow guaranteeing a transfer of an identical spatial position in the mouth. The lower model was mounted using a centric therapeutic relationship as the reference occlusal position (Figure 8-10). We opted for a rigid occlusal orthosis (thermo-polymerizable resin) of complete muscular reconditioning on the lower arch, and contrary to being smooth as it is customary the latter is indented by the maxillary antagonist teeth, its manufacture estimated more reliable and reproducible; the occlusal relation is balancing, controlling the mandibular position induced (therapeutic centered relation) (Figure 10) [9-12].

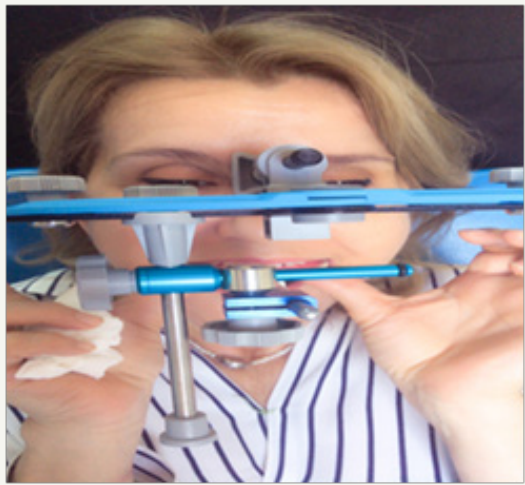

Figure 9: Facial arc on place, font view.
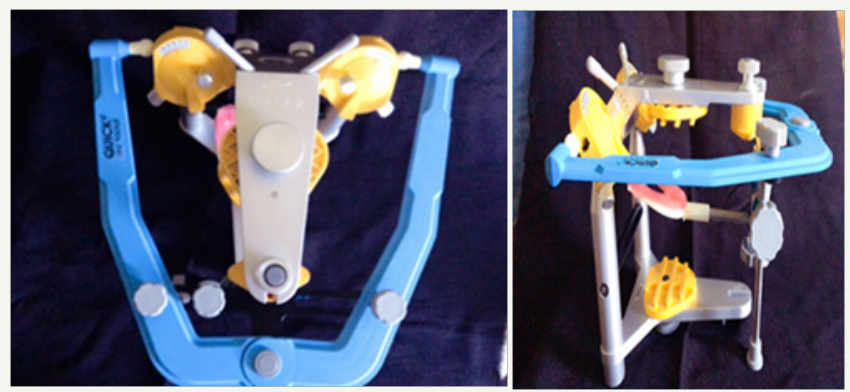

Figure 10a \& b: Arc facial monted on articulateur SAMII, seen from above. B: Profile view.

This splint was balanced in the mouth on the day of its installation, so that we obtain contact points of uniform intensity and distributed uniformly at its occlusal surface in a static position and a slight anterior guide, from canine to canine, providing posterior disocclusion in centric movements (Figure 11 \& 12).

Figure 10c \& d: Occlusal splint realized on SAM II (state of wax). 


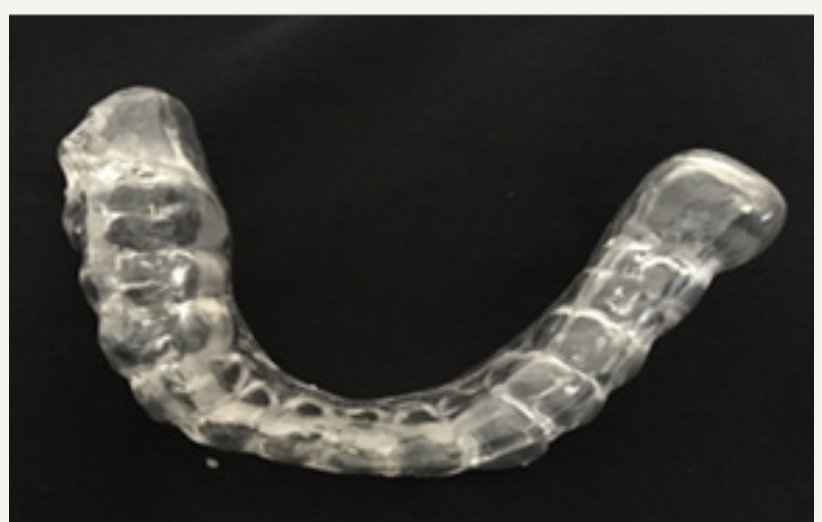

Figure 11: Occlusal splint before equilibration.

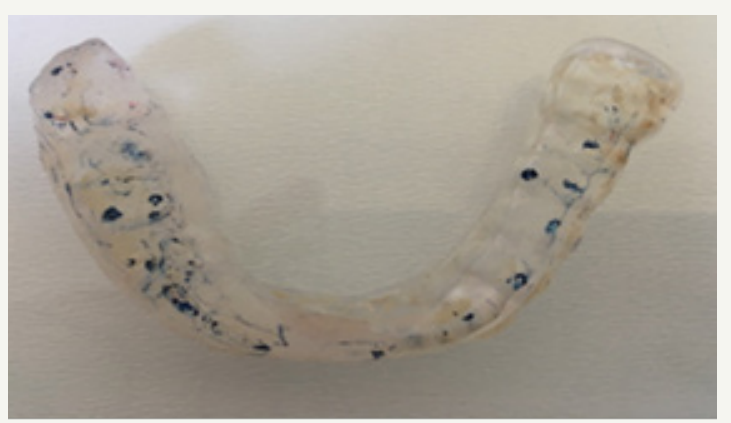

Figure 12: Occlusal splint after equilibration in mouth noted the distribution of occlusal contacts.

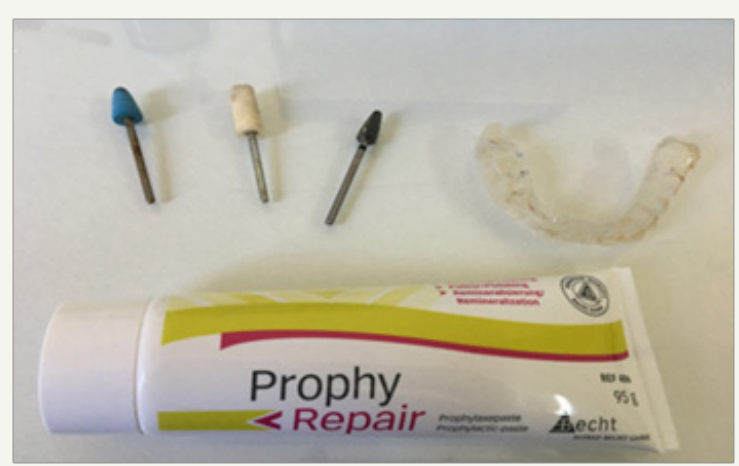

Figure 13: Polishing paste and silicone burs.

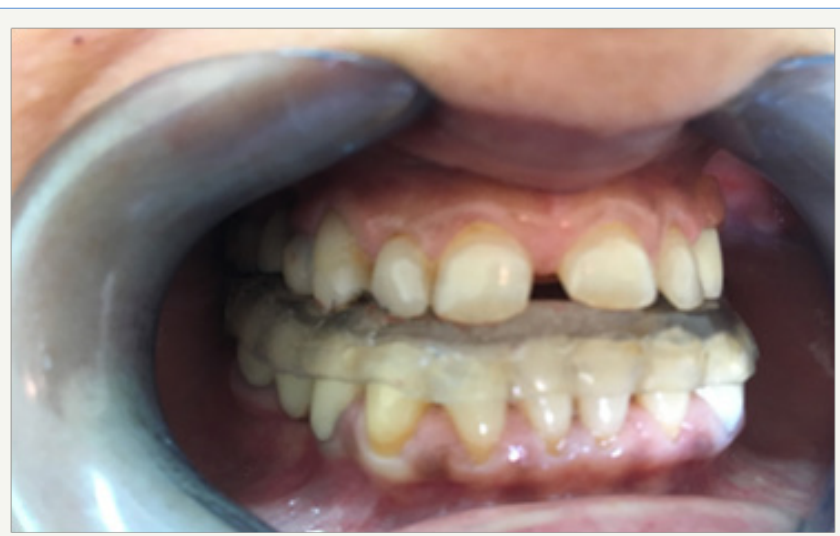

Figure 14: Occlusal splint in mouth.
The adjustment is made with a conical or cylindrical tungsten carbide or resin bur then polished to prevent the patient from being injured (Figure 13). In fact, the splint conditions the patient to a new articular and occlusal position (Figure 14). After three months of wearing the occlusal splint and weaning (Figure 15), a clinical control examination was performed which resulted in the disappearance of DTM signs.

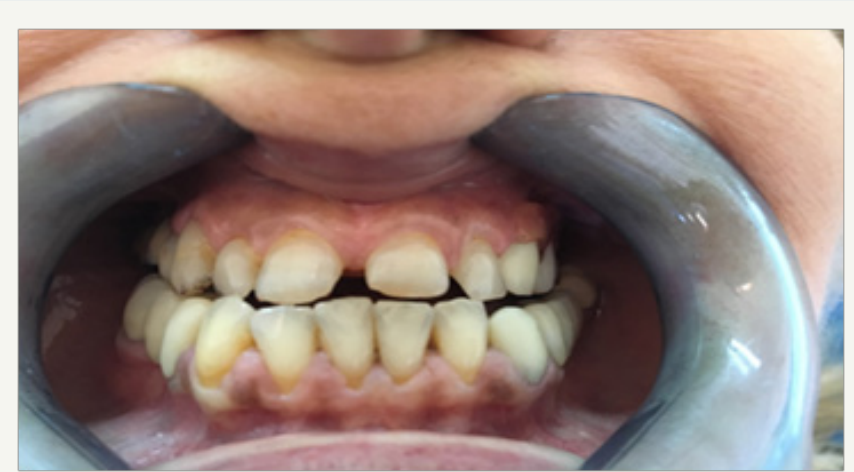

Figure 15: Occlusion after 3 months of wearing occlusal splint.

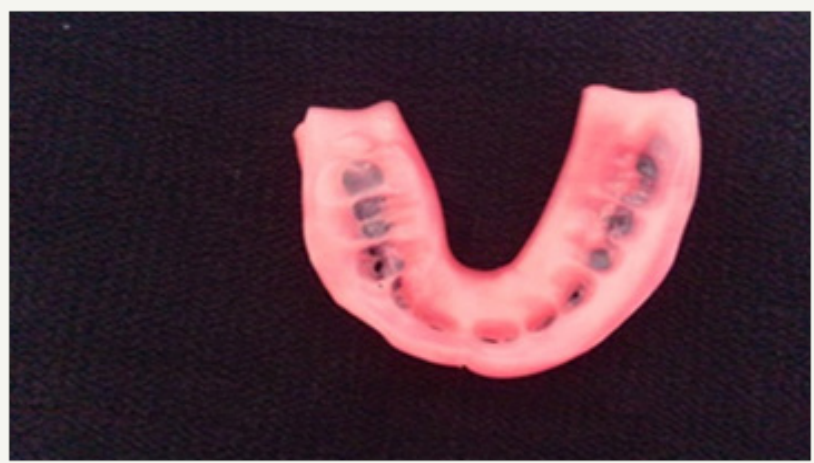

Figure 16: Occlusal check bite.

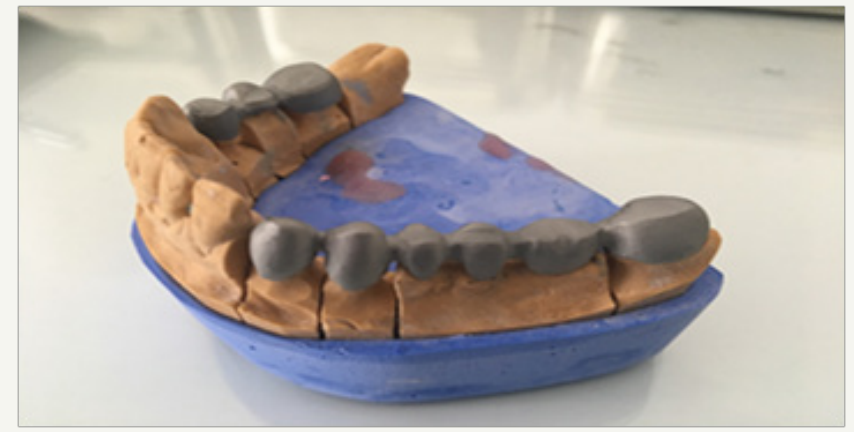

Figure 17: Fractional lower model with metal armature.

The new centric relation resulting from the orthopedic treatment is then recorded via an occlusal bite in non-perforated wax (Figure 16-20). Occlusal analysis consists of studying the static and dynamic occlusion before and after wearing the occlusal splint. Articulated paper is used to identify deflection points and premature contacts and teeth under occlusion or under guidance. 


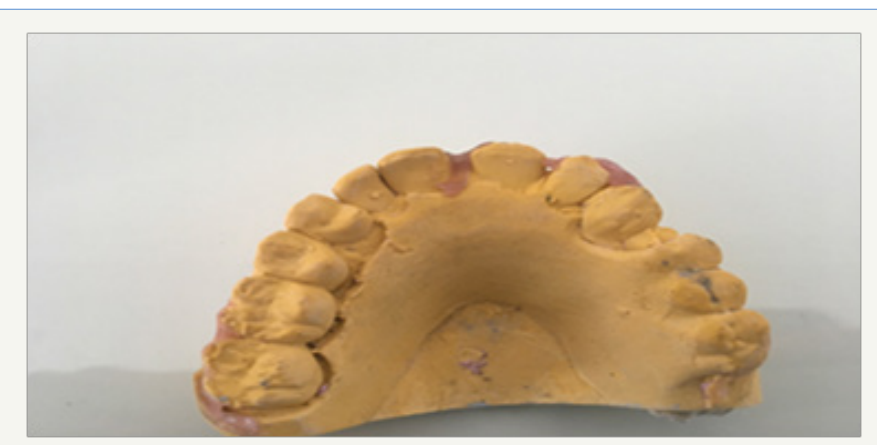

Figure 18: Upper model.

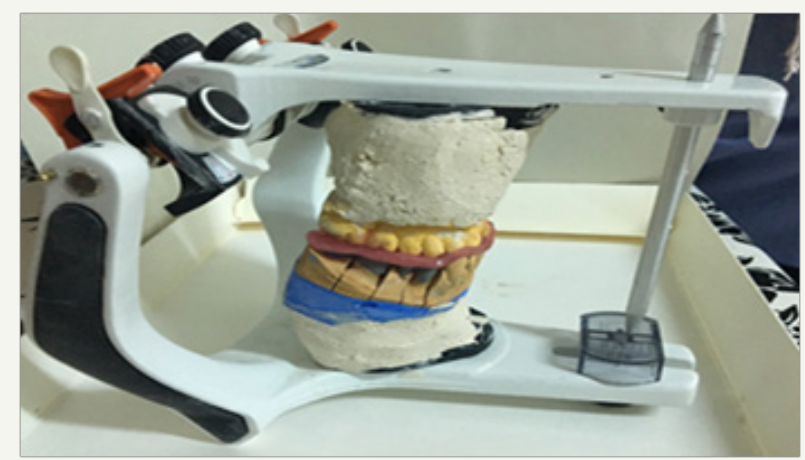

Figure 19: Armature monted on articulateur Bio art A 7 Plus.

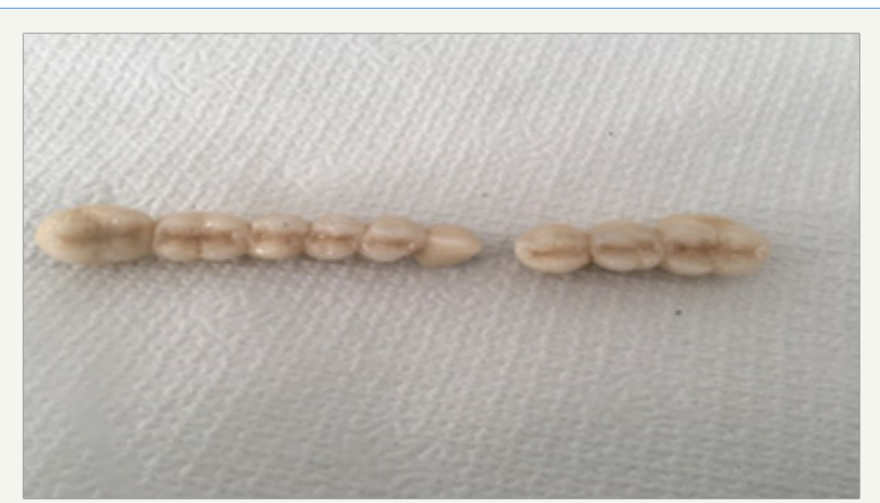

Figure 20: Metal-ceramic prosthetic bridge.

The actual prosthetic treatment begins with the cancelling the existing bridges; resumption of the size of the stumps and impression double mixture of the dental preparations all sent to the laboratory of dental prosthesis for possible metal armatures which will be realized on a fractional model and mounted on articulator semi adaptable programmed according to the real values, once received they will be tried in mouth ; once the cervical limits are validated; they will be sent to the laboratory for the preparation of the biscuit and the assembly of the ceramic. A six-month provisional cementation of the metallo-ceramic bridges, followed by permanent sealing, will close the treatment (Figure $21 \& 22$ ).

\section{Results}

a. The absence of posterior wedging associated with an inverted and non-functional anterior guide has a strong responsibility in the etiology of TMD.

b. The positive diagnosis is a disc displacement with reduction at the end of the opening movement.

c. The increase in the vertical dimension related to the thickness of the occlusal splint was well tolerated by the patient because the initial DV was undervalued (Figure 8).

d. The beneficial effect of the splint is essentially and quickly analgesic. This treatment is temporary, etiological treatment is required.

e. The axiographic recording at the end of the therapeutic approach has changed, as the value of the condylar slope, which has passed from $50^{\circ}$ to $53^{\circ}$ witness of harmonious condylar course with the disappearance of the articular meniscus jump (Figure 21 \& 23).

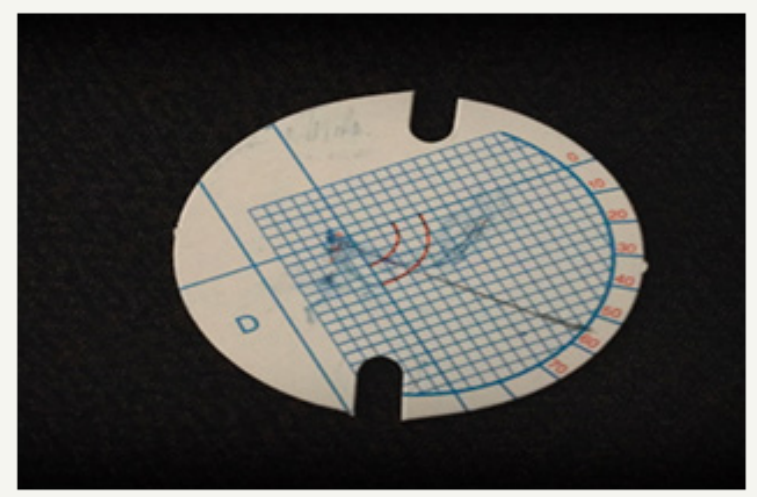

Figure 21: Axiography registration in the end of the global rehabilitation.

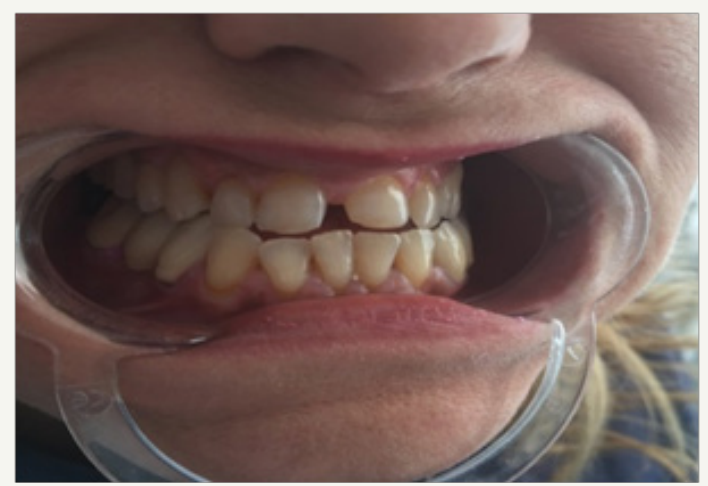

Figure 22: 12: Occlusion in the end of treatment.

\section{Discussion and Conclusion}

The cause-and-effect relationship between occlusion (absence of posterior wedging) and temporomandibular dysfunction has not yet been established.

The logic of our approach was to do:

i. A thorough clinical examination

ii. An axiography recording of the condylar slope before and after treatment and to make the diagnosis of joint pathology 
iii. Realize a splint indented balanced harmoniously in the mouth to stabilize the joint, protect the teeth, and redistribute the forces (occlusal)

iv. Mount the models of the patient on articulator according to the new occlusal position with the real condylar values
$\left(\mathrm{PC}=53^{\circ}, \mathrm{AB}=18,62\right)$

v. We obtained at the end of the treatment, a stable and unique occlusion without muscular constraints at centric relation at the good vertical dimension.

The patient plans to make porcelain veneers later.

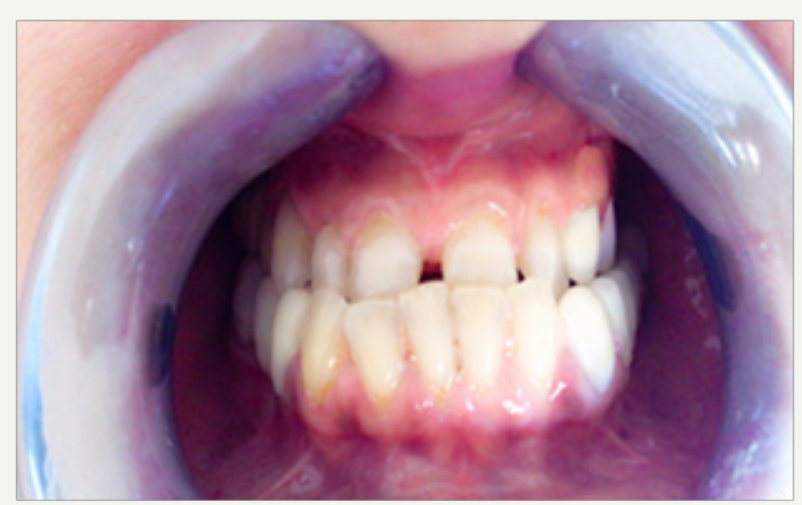

Figure 23a \& b: Clinical case before and after treatment.

\section{References}

1. Rychler H, Ramin M, Claude B (2000) Les douleurs de l'articulation temporo-mandibulaire. Lovaine Medical 119(9): S490-S496.

2. Major PW, Nebbe B (1997) Use and effectiveness of splint appliance therapy: review of literature. Cranio 15(2): 159-166.

3. (2016) Société Française de Stomatologie, Chirurgie Maxillo-Faciale et Chirurgie Orale: Orthèses (Gouttières) occlusales: indications dans les Dysfonctions Temporo-Mandibulaires. Recommandations de Bonne Pratique.

4. Goulet JP, Lavigne G (2004) Mieux comprendre et traiter les problèmes temporomandibulaires. Le Médecin du Québec 39(7): 38-48.

5. Orthlieb JD, Darmouni L, Jouvin J, Pedinielli A (2015) Dysfonctions occlusales: anomalies de l'occlusion dentaire humaine. EMC 10(1) : 1-11.

6. Österberg T, Carlsson GE, Wedel A, Johansson U (1992) A cross-sectional and longitudinal study of craniomandibular dysfunction in an elderly population. J Craniomandib Disord 6(4): 237-245.

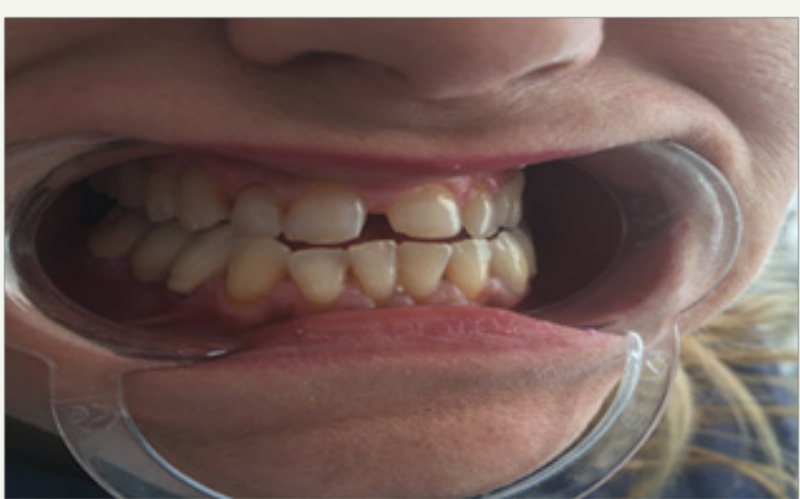

7. Öwall B, Kayser AF, Carlsson GE (1998) Prothese dentaire: dans Principes et stratégies thérapeutiques. Elsevier Masson, France, p. 256.

8. Iacopino AM, Wathen WF (1993) Craniomandibular disorders in the geriatric patient. J Orofac Pain 7(1): 38-53.

9. Marc M (1992) Vieillissement articulaire. Le Journal de l'Edgwise 26: 129-140.

10. Harriman LP, Snowdon DA, Messer LB, Rysavy DM, Ostwald SK, et al. (1990) Temporomandibular joint dysfunction and selected health parameters in the elderly. Oral Surg Oral Med Oral Pathol 70(4): 406413.

11. Rozencweig D (1994) Algies et dysfonctionnements de l'appareil manducateur. Editions Cdp, Paris, France.

12. Greene CS (1994) Temporomandibular disorders in the geriatric population. J Prosthet Dent 72(5): 507-509.
Creative Commons Attribution 4.0 International License

For possible submissions Click Here

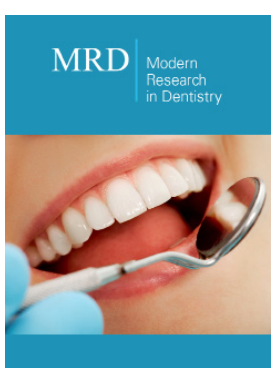

Modern Research in Dentistry

\section{Benefits of Publishing with us}

- High-level peer review and editorial services

- Freely accessible online immediately upon publication

- Authors retain the copyright to their work

- Licensing it under a Creative Commons license

- Visibility through different online platforms 